\title{
Subacromial bursitis related to HIV infection: case report
}

\begin{abstract}
Objective: Describe a subacromial bursitis at the right shoulder of a 45 -year-old male subject. The patient has been living with HIV/AIDS for 22 years. Methods: The ultrasonography and the MRI revealed the presence of a pronounced subacromial effusion, with an inflammatory reaction of adjacent tissues. The tumoration was handled firstly with a needle-puncture aspiration, with a thick liquid outflow, followed by an open drainage. Histopathological evaluation showed no evidence of any AIDS defining disease. There was complete remission of the infection after five months thereafter the symptoms had started. Conclusion: After reviewing the scarce literature in the area, no reports of subacromial bursitis in HIV/AIDS patients were found. The authors point out that, although rare, this disease should be considered as differential diagnosis of shoulder diseases in HIV-infected subjects.
\end{abstract}

Keywords: shoulder; bursitis; HIV.

[Braz J Infect Dis 2010;14(6):645-646]@Elsevier Editora Ltda.

\section{TO THE EDITOR}

Osteoarticular manifestations have been regularly reported in long term HIV-infected patients on highly active antiretroviral therapy. The most frequent manifestations are: osteoporosis/osteopenia of varying severity, osteonecrosis of the femoral head, frozen shoulder and the carpal tunnel syndrome. ${ }^{1,2}$

The authors describe a case of subacromial bursitis at the right shoulder of a 45-year-old male subject. The patient had a diagnosis of HIV infection in 1988, and received long-lasting antiretroviral therapy. The patient was currently being treated with Tenofovir, Lamivudine and Estavudine, and had a CD4 count of 400 cells $/ \mathrm{mm}^{3}$ and undetectable HIV viral load. One month thereafter the subject presented at our service complaining of pain at the right shoulder, with signs of effusion, increased local temperature and functional limitation of that joint. There was no history of trauma or repetitive movement. While the shoulder X-ray revealed no abnormalities, the ultrasonography and the MRI (Figure 1) demonstrated the presence of a mild effusion in the subacromial space, synovial thickening, with an inflammatory reaction of adjacent tissues, with- out degenerative changes in rotator cuff tendons. It was then decided to perform a needle puncture aspiration of the subacromial space draining a thick liquid with blood clots, followed by an open drainage, with mechanical cleaning and surgical debridement. Histopathological evaluation showed no evidence of any AIDS defining disease. Cultures for aerobic and anaerobic bacteria, fungi and mycobacteria turned out negative. There was complete remission of the infection complication.

Figure 1: MRI of the right shoulder revealed the presence of a large subacromial effusion.

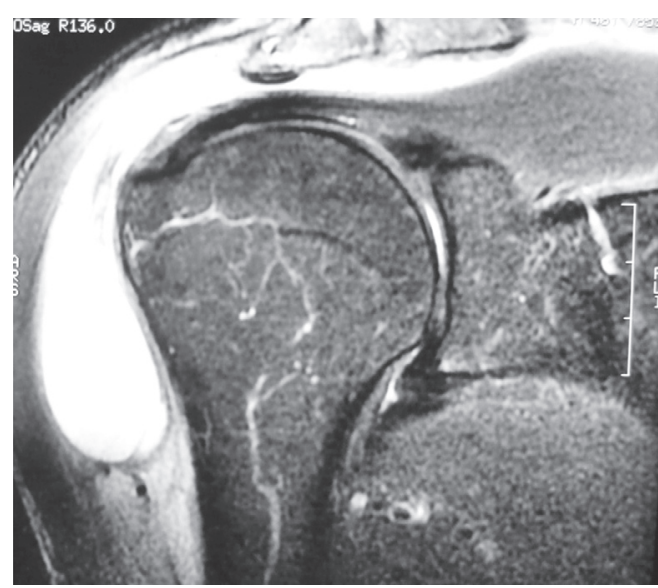

Authors

Benno Ejnisman ${ }^{1}$

Eduardo Antônio de Figueiredo ${ }^{2}$

Bernardo Barcellos Terra ${ }^{2}$

Ana Lucia L Munhoz

Lima

David E Uip ${ }^{4}$

${ }^{1} \mathrm{PhD}$, Orthopedics, Unifesp - Chief of Shoulder and

Elbow of the Centro de

Traumatologia do Esporte. ${ }^{2}$ Member of SBOT

(Sociedade Brasileira de Ortopedia e Traumatologia) - Resident in Shoulder and Elbow Surgery at the Centro de Traumatologia do Esporte (CETE/

UNIFESP)

${ }^{3} \mathrm{PhD}$, Infectology, USP Infection Service Chief at IOT-HCFMUSP.

${ }^{4}$ Associate Professor at USP

- Full Professor at Medical

Clinic of ABC Medical College.

Submitted on: 07/19/2010 Approved on: 10/28/2010

Affiliation: Instituto Cohen de Ortopedia e Reabilitação and Hospital Israelita Albert Einstein

Correspondence to: Eduardo Antônio de Figueiredo Av. 11 de junho, 415 - Vila Clementino - 04041-051, São Paulo, SP Phone: (11) 5579-4809 / 8453-0737

E-mail: eduardoafigueiredo @terra.com.br

We declare no conflict of interest. 
HIV-infected patients may present with several pain syndromes. However, the shoulder has been an uncommon site of musculoskeletal pain. ${ }^{3}$ Frozen shoulder, disease characterized by progressive movement amplitude limitation of the glenoumeral joint, is not considered as a adverse effect of antiretroviral therapy. However, several published articles in the literature suggest this association. ${ }^{4}$ No previous reports of subacromial bursitis in HIV-infected patients could be identified. Buskila, in $1987,{ }^{5}$ reported on two cases in the topography of the olecranon region, but different from the abovementioned subject, as they were caused by Staphylococcus aureus infection. Aseptic bursitis, as it occurs in inflammatory diseases, such as gout, rheumatoid arthritis or trauma is considered a risk factor for the development of septic bursitis. We believe that early diagnosis, as well as effective surgical drainage were decisive for the favourable outcome of the reported patient.

\section{REFERENCES}

1. Lima ALLM, Zumiotti AV, Camanho GL, Benegas E, Santos ALG, DElia CO et al. Osteoarticular complications related to HIV infection and highly active antiretroviral therapy. Braz J Infect Dis. 2007; 11(4): 426-9.

2. Lima ALLM, Godoy AL, Oliveira PRD, Gobbi RG, Silva CA, Martino PB et al. Alterações ortopédicas na AIDS. Rev. bras. ortop.2009;44(3): 186-90.

3. Atalay A, Özdemir O, Guven GS, Basgöze O: HIV infection and shoulder pain: a challenging case. Rheumatol Int. 2006; 26: 680-682

4. De Witte S, Bonnet F, Bonarek M, Lamarque P, Morlat P, Receveur MC et al: Adhesive capsulitis of the shoulder in an HIV patient treated with nelfinavir. AIDS. 2002; 16: 1307-8.

5. Buskila D; Tenenbaum J: Septic bursitis in human immunodeficiency virus infection. J Rheumatol. 1989; 16: 1374-6. 